\title{
Ambient pH and the Response to Chemical Alarm Cues in Juvenile Atlantic Salmon: Mechanisms of Reduced Behavioral Responses
}

\author{
Antoine O. H. C. Leduc* \\ Aquatic Ecology Research Laboratories, University of British Columbia, \\ 2201 Main Mall, Vancouver, British Columbia V6J 2J2, Canada \\ Ellie Roh and Camille J. Macnaughton \\ Department of Biology, Concordia University, \\ 7141 Sherbrooke Street West, Montréal, Québec H4B 1R6, Canada \\ FREDERIC BENZ \\ Département des Sciences de la Nature, Cégep du Vieux Montréal, \\ 255 Ontario Street East, Montréal, Québec H2X 1X6, Canada

\section{JORDAN ROSENFELD} \\ Aquatic Ecology Research Laboratories, University of British Columbia, \\ 2201 Main Mall, Vancouver, British Columbia V6J 2J2, Canada \\ GRANT E. BROWN \\ Department of Biology, Concordia University, \\ 7141 Sherbrooke Street West, Montréal, Québec H4B 1R6, Canada
}

\begin{abstract}
Even at sublethal concentrations, various anthropogenic pollutants may disrupt the transfer of chemosensory information, often inducing maladaptive behavioral responses. Recent studies of freshwater prey fishes have shown impaired abilities to respond to damage-released chemical alarm cues from conspecifics under weakly acidic conditions $(\mathrm{pH} \sim 6.0)$. Several factors acting individually or collectively may account for such chemosensory impairment. By itself, acidification may chemically disrupt the alarm cues and affect fish olfactory functions. Alternatively, differences in local environmental conditions may affect biochemical composition, quantity of chemical alarm cues produced by epidermal tissue, or both, leading to variations in alarm response. Our goal was to assess whether the ability to produce and detect conspecific chemical alarm cues is similar in individuals reared under neutral versus acidic conditions. We conducted two experiments in which we measured the behavioral response of wild juvenile Atlantic salmon Salmo salar exposed to chemical alarm cues. In particular, we looked for differences in the ability of individual fish to (1) produce alarm cues capable of eliciting consistent antipredator behavior in conspecifics and (2) detect alarm cues upon the fish's introduction into a stream with a $\mathrm{pH}$ differing from that of the stream of origin; the latter experiment involved reciprocal transplant of fish between neutral ( $\mathrm{pH}$ range $\sim 7.0-7.3$ ) and acidic ( $\mathrm{pH}$ range $\sim 5.9-6.3$ ) sites. Our results demonstrate that the ability to produce and respond to chemical alarm cues is maintained in Atlantic salmon reared under acidic conditions and did not differ from that of fish reared under neutral conditions. Overall, these data suggest that no permanent olfactory damage occurred under reduced $\mathrm{pH}$ and, likewise, no significant difference in functional alarm cue production existed between Atlantic salmon reared under neutral and acidic conditions. Short-term reduction in olfactory sensitivity and degradation of the chemical alarm cues under acidic conditions are the likely mechanisms affecting detection of these important chemicals by prey fish.
\end{abstract}

Predation is a strong selective agent, shaping the ability of prey to detect local predation threats and respond in a context-appropriate manner (Lima and Dill 1990; Abrams 1995; Lima 1998). While many sensory

\footnotetext{
* Corresponding author: a.leduc@fisheries.ubc.ca
}

Received February 3, 2009; accepted August 10, 2009 Published online November 5, 2009 modalities may be used to assess local predation risks, chemical cues used in predator avoidance are widespread among vertebrate and invertebrate prey species (Turner et al. 2000; Persons et al. 2001; Brown and Chivers 2005). Of the various types of chemical alarm cues used in risk assessment (Wisenden 2000), damagereleased chemical alarm cues (i.e., those that are passively released upon mechanical damage to the 
epidermis) are commonly found among a wide variety of taxonomically diverse aquatic prey species (Smith 1992, 1999; Chivers and Smith 1998; Brown 2003). Given that predation is often the agent of release, this type of alarm cue should represent a reliable indication of local risk. When detected by nearby conspecifics, these chemical cues may elicit dramatic increases in species-typical antipredator responses (Smith 1992; Chivers and Smith 1998; Leduc et al. 2006), which have been demonstrated to increase survival during staged encounters with natural predators (Mathis and Smith 1993; Mirza and Chivers 2000).

Unfortunately, chemosensory functions can be affected by anthropogenic chemical disturbances (reviewed by Lürling and Scheffer 2007). For example, even in sublethal concentrations, pesticides (Atchison et al. 1987; Little et al. 1990; Scholz et al. 2000), heavy metals (Scott et al. 2003; McPherson et al. 2004; Sandahl et al. 2007), and acidification (Åtland 1998; Brown et al. 2002; Tembo 2009) may impair the detection and response to chemical signals in wideranging organisms. As anthropogenic acidity may be far removed from its direct source (Rodhe et al. 1995), acidification may cause serious concerns for ecosystems that are not otherwise affected by human activity (reviewed by Schindler 1988). Recent laboratory and field experiments have shown reduced response to chemical alarm cues under weakly (sublethal) acidic conditions (i.e., $\mathrm{pH} \sim 6.0$; Brown et al. 2002; Leduc et al. 2006). For example, Leduc et al. (2004, 2006) showed reduced alarm responses in brook trout Salvelinus fontinalis and Atlantic salmon Salmo salar that were exposed to conspecific chemical alarm cues in acidic streams ( $\mathrm{pH}$ range $\sim 5.8-6.3$ ) compared with neutral streams $(\mathrm{pH}$ range $\sim 7.0-7.4)$.

Understanding the mechanisms involved in alarm function loss at low $\mathrm{pH}$ may help explain the differences in response to alarm cues between prey fish reared under different acidification regimes. For instance, work by Brown et al. (2002) suggests a molecular "degradation" of the chemical alarm cues in the presence of acid, which renders the cues nonfunctional. From this mechanism, a loss of response to the alarm cues may occur without physiological olfactory impairment of fish (Leduc et al. 2004; Smith et al. 2008). Another possibility, however, involves reduced olfactory abilities in fish (Moore 1994; Tembo 2007). Due to the presence of acids, lowered olfactory sensitivity may increase the concentration threshold for the detection of chemical signals, making detection difficult at environmentally relevant concentrations (Moore 1994). Consequently, after prolonged periods of acidification, significant olfactory damage may occur, thereby impeding the detection of chemical cues even after a return to neutral $\mathrm{pH}$ conditions (i.e., extended period of recovery time may be necessary; Brown et al. 1982; Moore 1994). A third, nonmutually exclusive, mechanism exists in which the ambient $\mathrm{pH}$ alters either the quality or quantity of chemical alarm cue produced. For example, juvenile convict cichlids Cichlasoma nigrofasciatum that were fed varying diets produced alarm cues that differed in efficiency for triggering an alarm response in conspecifics (Brown et al. 2004; Roh et al. 2004). Similarly, Chivers et al. (2007) demonstrated that an increased volume of chemical alarm cues was produced from fish epidermis in the presence of skin pathogens. Thus, ambient acidity and differences in environmental conditions might affect the environmentspecific ability to detect chemosensory information, the production of the alarm cue itself, or both.

In this study, we tested the ability of juvenile Atlantic salmon to respond to (and thus detect) chemical alarm cues and their ability to produce chemical alarm cues under varying $\mathrm{pH}$ conditions. In addition, we considered the roles of environment versus local effects in the variation of antipredator response to chemical alarm cues. We asked the following questions: (1) do Atlantic salmon reared under acidic conditions retain the ability to produce a recognizable alarm cue despite their inability to exhibit an alarm response; and (2) do Atlantic salmon reared under acidic conditions have reduced olfactory abilities to detect chemical alarm cues in comparison with conspecifics found under neutral conditions? To address the above questions, we conducted two experiments. In the first experiment, we tested for a difference in alarm response intensity after exposures to chemical alarm cues from Atlantic salmon of different origins (i.e., reared in neutral or weakly acidic streams) and from a sympatric prey guild member species when tested under neutral conditions (i.e., where the detection of the alarm cues has been shown to occur). This procedure allowed us to assess whether populations from acidic and neutral streams produced chemical alarm cues having a similar potential to elicit antipredator behavior. In the second study, we conducted a reciprocal transplant experiment (see below) between Atlantic salmon reared in streams with acidic and neutral $\mathrm{pH}$ levels (mean $\mathrm{pH} \sim 7.2$ and 6.10 , respectively) and assessed whether environmental or long-term olfactory impairment from acidity better explained the absence of an alarm response.

\section{Methods}

\section{Test Sites}

Field observations were conducted in Northumberland County, New Brunswick, Canada, in two tributaries of the Little Southwest Miramichi River: 


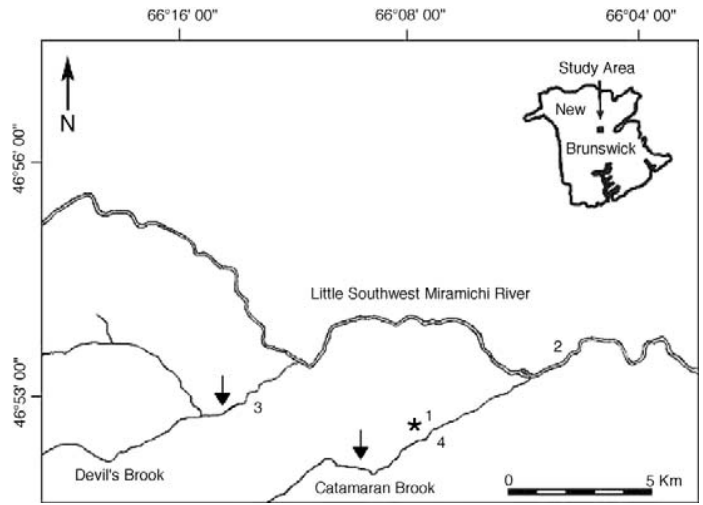

FIGURE 1.-Locations of study sites in New Brunswick, Canada, used for experiment 1 (asterisk = study site in Catamaran Brook; injury-released alarm cues were generated from Atlantic salmon collected at [1] Catamaran Brook, [2] Little Southwest Miramichi River, and [3] Devil's Brook and from [4] eastern blacknose dace in Catamaran Brook) and experiment 2 (arrows $=$ study sites $[\sim 30 \mathrm{~m}$ long] containing enclosures in Catamaran and Devil's brooks). Inset (top right corner) shows the location of the study area within New Brunswick.

Catamaran Brook (approximately 46 $51^{\prime} 49^{\prime \prime} \mathrm{N}$, $66^{\circ} 09^{\prime} 54^{\prime \prime} \mathrm{W}$ ) and Devil's Brook (approximately $46^{\circ} 52^{\prime} 40^{\prime \prime} \mathrm{N}, 66^{\circ} 13^{\prime} 75^{\prime \prime} \mathrm{W}$; Figure 1). Catamaran and Devil's brooks are natural nursery streams used by wild Atlantic salmon (Cunjak et al. 1993; Johnston 1997) and are located in mature forests exposed to little or no direct human disturbance effects aside from potential acid precipitation (Leduc et al. 2006, 2007). A large proportion of the region is underlain by poorly weatherable bedrock, including granite with little acid buffering capacity (Department of Energy, Mines, and Resources Canada 1991). Our data (see below) and data from Leduc et al. $(2006,2007)$ reveal persistent differences in ambient acidity from 2003 to 2006 between Catamaran Brook (mean $\mathrm{pH}$ range $=7.15$ 7.35) and Devil's Brook (mean pH range $=5.85-6.09$ ).

\section{Collection and Extraction of Chemical Stimulus Types}

For both experiments, we collected chemical alarm cues from conspecific donors captured in the Little Southwest Miramichi River (experiments 1 and 2), Catamaran Brook (experiment 1), and Devil's Brook (experiment 1; Figure 1). In all cases, donors were collected using a backpack electrofisher (Smith-Root, Vancouver, Washington). To ensure that alarm cue solutions from Atlantic salmon donors came from sites of suitable acidity, we measured the stream $\mathrm{pH}$ (using a MultiLine P4 meter; WTW, Weilheim, Germany) before and after capture of the fish (Table 1). Donors were euthanized via cervical dislocation. We removed skin fillets from either side of the donor's body and immediately placed the skin into untreated, ice-chilled well water with an approximate $\mathrm{pH}$ of 7.10. Skin fillets were then homogenized, filtered through polyester filter floss, and diluted to the desired final volume with the addition of well water. We collected sufficient skin (Table 1) such that the final concentration of alarm cues was approximately $0.08 \mathrm{~cm}^{2} / \mathrm{mL}$ of solution. This concentration has previously been shown to reliably elicit antipredator responses in stream-dwelling juvenile Atlantic salmon (Leduc et al. 2006, 2007). For experiment 1, we also used alarm cues from a sympatric prey guild member found in Catamaran Brook, the eastern blacknose dace Rhinichthys atratulus (Cunjak 1995), as prey may learn to detect and respond to chemical alarm cues from other species with which they are sympatric (i.e., heterospecific response; Chivers et al. 2002; Brown and Chivers 2005). Antipredator response to heterospecific cues may confer survival benefits (Mirza and Chivers 2002); thus, we included this sympatric alarm cue for comparison with conspecific Atlantic salmon alarm cues originating from different sites. As a control for the injection procedure, we used stream water. Stimuli were frozen in $20-\mathrm{mL}$ aliquots at $-20^{\circ} \mathrm{C}$ until required.

TABLE 1.- Stream pH range at the time of capture, number of donors, mean standard length (SL) of donors, and total area of skin fillets $\left(\mathrm{cm}^{2}\right)$ collected to generate damage-released chemical alarm cues from each population of juvenile Atlantic salmon or eastern blacknose dace used in experiments (exp.) 1 and 2 conducted in New Brunswick streams.

\begin{tabular}{|c|c|c|c|c|c|c|}
\hline Species and site & $\begin{array}{c}\text { Stream } \\
\mathrm{pH} \text { range }\end{array}$ & $\begin{array}{c}\text { Number of } \\
\text { donors }\end{array}$ & $\begin{array}{c}\text { Mean } \\
\mathrm{SL} \pm \mathrm{SD} \\
(\mathrm{mm})\end{array}$ & $\begin{array}{l}\text { Skin area } \\
\left(\mathrm{cm}^{2}\right)\end{array}$ & $\begin{array}{c}\text { Well-water } \\
\text { volume } \\
(\mathrm{mL})\end{array}$ & $\begin{array}{c}\text { Alarm cue } \\
\text { concentration } \\
\left(\mathrm{cm}^{2} / \mathrm{mL}\right)\end{array}$ \\
\hline \multicolumn{7}{|l|}{ Atlantic salmon } \\
\hline Little Southwest Miramichi River (exp. 2) & $7.04-7.11$ & 16 & $66.0 \pm 2.3$ & 79.6 & 917 & 0.086 \\
\hline Little Southwest Miramichi River (exp. 1) & $7.12-7.20$ & 12 & $63.7 \pm 2.4$ & 57.1 & 658 & 0.087 \\
\hline Catamaran Brook (exp. 1) & $7.22-7.34$ & 5 & $66.2 \pm 3.4$ & 32.7 & 367 & 0.089 \\
\hline Devil's Brook (exp. 1) & $5.98-6.12$ & 6 & $66.0 \pm 2.7$ & 35.8 & 401 & 0.089 \\
\hline \multicolumn{7}{|l|}{ Eastern blacknose dace } \\
\hline Catamaran Brook (exp. 1) & $7.22-7.34$ & 7 & $55.0 \pm 1.4$ & 28.6 & 323 & 0.0885 \\
\hline
\end{tabular}


TABLE 2.-Mean $( \pm \mathrm{SE})$ values of physical and chemical variables for each alarm cue stimulus treatment tested in Catamaran Brook (neutral stream pH), New Brunswick. The origin and species of alarm cue donors used in experiment 1 are indicated in column headings.

\begin{tabular}{lccccc}
\hline & \multicolumn{3}{c}{ Atlantic salmon } & & \\
\cline { 2 - 4 } \multicolumn{1}{c}{ Variable } & $\begin{array}{c}\text { Catamaran } \\
\text { Brook }\end{array}$ & $\begin{array}{c}\text { Little Southwest } \\
\text { Miramichi River }\end{array}$ & $\begin{array}{c}\text { Devil's } \\
\text { Brook }\end{array}$ & $\begin{array}{c}\text { Blacknose dace } \\
\text { (Catamaran Brook) }\end{array}$ & $\begin{array}{c}\text { Well water } \\
\text { (control) }\end{array}$ \\
\hline $\mathrm{pH}$ & $7.29 \pm 0.06$ & $7.27 \pm 0.09$ & $7.22 \pm 0.03$ & $7.34 \pm 0.08$ & $7.35 \pm 0.02$ \\
Dissolved oxygen (\%) & $98.8 \pm 0.14$ & $97.8 \pm 0.09$ & $96.2 \pm 0.11$ & $96.9 \pm 0.05$ & $98.1 \pm 0.03$ \\
Water temp ( $\left.{ }^{\circ} \mathrm{C}\right)$ & $17.0 \pm 0.06$ & $17.2 \pm 0.12$ & $17.6 \pm 0.07$ & $17.4 \pm 0.08$ & $17.8 \pm 0.11$ \\
Velocity (m/s) & $0.26 \pm 0.13$ & $0.33 \pm 0.12$ & $0.33 \pm 0.06$ & $0.28 \pm 0.24$ & $0.27 \pm 0.20$ \\
Depth (m) & $0.23 \pm 0.22$ & $0.29 \pm 0.26$ & $0.25 \pm 0.31$ & $0.26 \pm 0.19$ & $0.28 \pm 0.73$ \\
Cloud cover (\%) & $52 \pm 14$ & $55 \pm 09$ & $50 \pm 12$ & $61 \pm 10$ & $48 \pm 19$ \\
Substrate complexity & $82 \pm 0.7$ & $83 \pm 0.9$ & $90 \pm 0.2$ & $88 \pm 0.5$ & $84 \pm 0.1$ \\
\hline
\end{tabular}

\section{Experiment 1: Testing for Population Differences in Alarm Cue Production}

Experiment 1 was conducted during July 2005 in a 200-m stretch of Catamaran Brook (Figure 1), a pH neutral stream in which the chemical alarm system has been shown to be functional (i.e., to elicit a consistent antipredator response; Leduc et al. 2006). The experiment consisted of five treatments: four different alarm cue sources (i.e., donor origin) and a control of stream water. Alarm cue solutions were generated from (1) Catamaran Brook Atlantic salmon (same site, neutral pH), (2) Little Southwest Miramichi River Atlantic salmon (different site, neutral pH), (3) Devil's Brook Atlantic salmon (different site, weakly acidic $\mathrm{pH})$, (4) Catamaran Brook eastern blacknose dace (same site, heterospecific alarm cue), and (5) well water. Details pertaining to the generation of the alarm cue solutions are reported in Table 1. The purpose of this experiment was to test for differences in the "potential" of alarm cues from individual Atlantic salmon reared under different $\mathrm{pH}$ conditions to trigger an alarm response in conspecifics reared under neutral conditions. A second goal was to test for any siterelated effects of the alarm cues (i.e., whether the alarm response to "in-site" versus "off-site" alarm cues differed). We predicted that if ambient acidity had any effect on the production or quality of the alarm cues, we would observe differences in alarm response intensity between alarm cue exposures originating from neutral and acidic sites (i.e., Devil's Brook alarm cues should elicit a weaker response than alarm cues from either Catamaran Brook or Little Southwest Miramichi River). Alternatively, if the ability to respond to chemical alarm cues reflects local adaptations, we predicted that the alarm cues originating from the test site (cues from both Atlantic salmon and eastern blacknose dace) would elicit a significantly greater alarm response than the two Atlantic salmon alarm cues from off site (i.e., Devil's Brook and Little Southwest Miramichi River).

Experimental protocol.-In Catamaran Brook, we chose a section with relatively homogeneous physical characteristics (Table 2) in which to conduct behavioral observations on individual Atlantic salmon. We videorecorded all alarm cue sensitivity trials using focal individuals that were found randomly while snorkeling in the test site. When a focal Atlantic salmon was found, the experimenter (A.O.H.C.L.) positioned himself approximately $1.5 \mathrm{~m}$ upstream from the test fish at an angle of approximately $45^{\circ}$ relative to the water current to minimize turbulence that might interfere with the test subjects. From this upstream position, we recorded the observation trials using a Sea View underwater video camera held by the experimenter. From this distance $(\sim 1.5 \mathrm{~m})$, behavioral observations on juvenile salmon can be conducted with ease and accuracy (Leduc et al. 2007). Prior to the start of all trials, we let the focal fish acclimate to the experimenter's presence until it behaved "normally" (i.e., it was feeding and moving). Observation trials were $10 \mathrm{~min}$ in duration and were divided into 5-min prestimulus and 5-min poststimulus observation periods. Immediately after the prestimulus observation period, we injected $20 \mathrm{~mL}$ of one of the five stimuli (including the water control) into the stream and immediately began the poststimulus observation period. We repeated this procedure moving from downstream to upstream and spacing trial sites by at least $4 \mathrm{~m}$ (i.e., larger than the $1.5-3.0-\mathrm{m}^{2}$ territory size typical of young-of-year [age-0] Atlantic salmon; Steingrímsson and Grant 2003). We conducted a total of 64 alarm cue sensitivity trials: 13 in response to Catamaran Brook Atlantic salmon alarm cues, 12 for Devil's Brook alarm cues, 12 for Little Southwest Miramichi River alarm cues, 14 for Catamaran Brook eastern blacknose dace alarm cues, and 13 for the stream water control.

After each trial, we measured a suite of environmental variables to reduce the probability that any 
observed differences could be attributed to small-scale habitat differences (Table 2). Water velocity was recorded at $5 \mathrm{~cm}$ below the water surface using a Flo-Mate velocity meter (Marsh-McBirney, Inc., Frederick, Maryland). We measured $\mathrm{pH}$, dissolved oxygen, and water temperature using a MultiLine P4 meter (WTW), and depth was measured using a 1-m ruler. In addition, we measured substrate complexity at the focal location of each test fish (i.e., the location where they received the stimulus) by taking one measurement parallel to water flow and one measurement perpendicular to water flow using a 1-m-long, flexible metal wire that we molded to the substrate (as in Keeley and Grant 1995). An index of complexity was obtained by measuring the linear distance between the ends of the wire after it was molded to the substrate. Since the metal wire had a length of $1 \mathrm{~m}$, a substrate complexity value of 1 would indicate that the substrate is flat (i.e., no complexity), while a lower number would indicate greater complexity.

Behavioral measures and statistical analysis.From the video recordings, we quantified the following for each focal Atlantic salmon during both the pre- and poststimulus observation periods: (1) time (s) spent moving, (2) number of foraging attempts, and (3) time (s) spent on the substrate. Time spent moving was defined as any observable displacement exceeding 1.0 body length (BL). Feeding attempts were defined as displacements of at least $0.5 \mathrm{BL}$, followed by a pecking motion typical of salmon striking at drifting prey. Time on the substrate was recorded as the time for which a focal fish was in physical contact with the substratum without changing its location. For each behavioral measure, we calculated the change between pre- and poststimulus observation periods and used these difference scores as dependent variables in all subsequent analyses. Videotapes were quantified blind to the treatment.

We tested for differences in stimulus type using analyses of variance (ANOVAs) for each behavioral measure. Post hoc comparisons were made with Fisher's probability of least-squared differences. We used the Statistical Package for the Social Sciences (SPSS) version 11 to conduct all statistical analyses.

\section{Experiment 2: Testing for Different Population Sensitivities to Alarm Cues}

In July 2004, we conducted a reciprocal transplant experiment between Catamaran Brook (neutral $\mathrm{pH}$ ) and Devil's Brook (acidic pH) that involved placement of an enclosure in each stream (see below). We used a $2 \times$ $2 \times 2$ factorial design with acidity level (Catamaran Brook versus Devil's Brook), fish origin (Atlantic salmon from Catamaran Brook versus Devil's Brook), and stimulus type (chemical alarm cue versus stream water) as factors. Atlantic salmon reared in Devil's Brook (weakly acidic) were tested in both a weakly acidic enclosure and a neutral stream enclosure. Likewise, Atlantic salmon from Catamaran Brook (neutral) were also tested in both a weakly acidic enclosure and neutral stream enclosure. Each fish was randomly exposed to one of the two stimuli and was tested only once. The purpose of this reciprocal transplant experiment was to compare the strength of the antipredator response between (1) Atlantic salmon exposed to an alarm cue in the home stream and (2) fish exposed to an alarm cue in a stream with a different ambient $\mathrm{pH}$. We predicted that if the ability to detect alarm cues was lost in Atlantic salmon reared under acidic conditions, then such individuals would not retain the ability to respond to the alarm cues even when tested under neutral conditions.

Experimental enclosures were constructed in each stream by fencing off individual channel units using 4.5-mm wire mesh supported by steel bars (as in Rosenfeld and Boss 2001). Enclosures were $6.0 \mathrm{~m}$ in length, $1.0 \mathrm{~m}$ in width, and $0.7 \mathrm{~m}$ in height and were installed parallel to the water current; each enclosure had a wire-mesh bottom skirt stapled to a 5- $\times 10-\times$ $60-\mathrm{cm}$ wooden plank buried under the substratum. To prevent fish from escaping, we also used a mesh bottom that we covered with gravel and cobbles (to produce natural substratum conditions). To reduce the possibility of visual transmission of an alarm response from alarm cue exposures (see Mathis et al. 1996) between test fish and to reduce intraspecific aggressive interactions (Imre et al. 2002; Blanchet et al. 2006), we arranged rows of natural boulders to half the depth of the enclosure (approximately $15 \mathrm{~cm}$ in height) placed perpendicular to the direction of flow in the enclosures. As such, with these rows, we created six visually isolated "compartments" (one division every linear meter). The enclosures were left undisturbed for a minimum of $48 \mathrm{~h}$ before conducting any behavioral trial.

Experimental protocol.-We conducted direct behavioral observation trials on test fish placed inside enclosures. In each enclosure, a total of 24 fish from the home stream and 24 fish from the other stream were tested. For each stream origin group, 12 fish were exposed to alarm cues and 12 fish were exposed to water. Thus, in a given enclosure (or at a given acidity level), 48 trials were conducted. We conducted 12 replicates per combination of treatments for a total of 96 observation trials ( 12 replicates $\times 2$ stream origins $\times$ 2 enclosure locations $\times 2$ stimulus types). Because of the limited number of enclosures (one in Catamaran Brook and one in Devil's Brook), experimental trials 
TABLE 3.-Mean ( \pm SE) values of physical and chemical variables for enclosures in Catamaran Brook and Devil's Brook, New Brunswick. One-way analysis of variance was used to assess differences in characteristics between the enclosures (significance at $P \leq 0.05 ; \mathrm{df}=1,95$ for all comparisons).

\begin{tabular}{lccrr}
\hline \multicolumn{1}{c}{ Variable } & Catamaran Brook & Devil's Brook & $F$ & $P$ \\
\hline $\mathrm{pH}$ & $7.26 \pm 0.18$ & $6.11 \pm 0.07$ & 15.418 & 0.001 \\
Dissolved oxygen $(\%)$ & $96.8 \pm 0.07$ & $95.8 \pm 0.12$ & 0.137 & 0.712 \\
Water temp $\left({ }^{\circ} \mathrm{C}\right)$ & $18.8 \pm 0.13$ & $16.4 \pm 0.09$ & 1.627 & 0.205 \\
Velocity $(\mathrm{m} / \mathrm{s})$ & $0.26 \pm 0.27$ & $0.21 \pm 0.26$ & 0.590 & 0.444 \\
Depth $(\mathrm{m})$ & $0.30 \pm 0.21$ & $0.33 \pm 0.10$ & 1.482 & 0.082 \\
Cloud cover $(\%)$ & $55 \pm 15$ & $47 \pm 18$ & 0.067 & 0.797 \\
Conductivity (mS/cm) & $27.18 \pm 0.09$ & $16.06 \pm 0.07$ & 18.301 & 0.001 \\
Substrate complexity & $91 \pm 0.11$ & $83 \pm 0.14$ & 0.746 & 0.059 \\
\hline
\end{tabular}

were run sequentially for $21 \mathrm{~d}$. We used a standardized Atlantic salmon alarm cue solution originating from donors collected in Little Southwest Miramichi River (Table 1) to minimize the confounding effects of using alarm cues from Atlantic salmon of different origins (i.e., Catamaran and Devil's brooks).

At least $24 \mathrm{~h}$ before each test trial (ranging from 24 to $27 \mathrm{~h}$ ), we placed six age- 0 Atlantic salmon in each of the two enclosures at a density of 1 individual $/ \mathrm{m}^{2}$, which represents a natural density in the study streams (Grant et al. 1998; Steingrímsson and Grant 2003). We randomly chose the origin (i.e., either Catamaran Brook or Devil's Brook) of the test fish to be placed in a given enclosure on a given day. The test subjects were captured using dip nets while snorkeling outside of the study sites (minimum of $30 \mathrm{~m}$ away from the enclosures). In this experiment, the test fish were placed inside the enclosure, while the observer (A.O.H.C.L.) was positioned outside of the enclosure. Behavioral observations were conducted as described above for experiment 1 , except that (1) we did not videotape the trials and (2) we recorded only the time spent moving and the number of foraging attempts. Stimuli were injected from outside of the enclosure (through the mesh) at approximately $0.5 \mathrm{~m}$ upstream from the focal fish. Stimuli were prepared by an assistant onshore so that the observer (A.O.H.C.L.) would have no knowledge of the treatment. Each test subject was individually exposed to one of two stimuli (randomly chosen) and was tested only once. To avoid exposing the test fish to multiple injected stimuli, we conducted the observations from the downstream-most fish to the upstream-most fish. Behavioral observations were directly recorded using a water-resistant stopwatch and a counter. On each testing day after the completion of all trials, we measured physical and chemical variables within each enclosure, taking measurements at $0.5 \mathrm{~m}$ from each end of the enclosure (i.e., at 0.5 and $5.5 \mathrm{~m}$ ) and averaging these values. The measured variables included $\mathrm{pH}$, depth, current speed, dissolved oxygen, conductivity, percent cloud cover, and water temperature (Table 3). After testing, Atlantic salmon were released at the location of their capture.

Statistical analysis.-As in experiment 1, we quantified the intensity of an alarm response by measuring the time (s) spent in movement and the number of feeding attempts during the pre- and poststimulus observation periods. We predicted that a reduction in feeding and movement would indicate the occurrence of an antipredator response (Chivers and Smith 1998). We tested for any overall effect of enclosure location (environmental acidity), test fish origin (Catamaran Brook versus Devil's Brook), and stimulus type (stream water versus chemical alarm cue) on the test fish's antipredator behavior intensity by using a multivariate ANOVA (MANOVA) with environment, fish origin, and stimulus as independent variables. Using subsequent MANOVAs, we further investigated the effects of stimulus type and fish origin on the test fish's antipredator response intensity for each stream separately.

To determine whether the behavioral responses were influenced by differences in habitat characteristics between streams, we compared the physical and chemical parameters (measured inside each enclosure) using an ANOVA (Table 3). To ensure that baseline activity was similar among test fish populations, we used ANOVA to compare the baseline (prestimulus) values of each behavioral measure between the two study streams and between the two stream origin groups. Our data met the assumption of normality. All statistical analyses were conducted using SPSS version 11.

\section{Results}

\section{Experiment 1: Testing for Population Differences in Alarm Cue Production}

The ANOVA with simple contrast revealed significant effects of stimulus type between pre- and poststimulus periods on the frequency of foraging 
attempts $\left(F_{4,59}=5.10, P=0.001\right)$, time moving $\left(F_{4,59}\right.$ $=4.98, P=0.002)$, and time on substrate $\left(F_{4,59}=3.56\right.$, $P=0.011)$. Post hoc comparisons demonstrated that each of the Atlantic salmon alarm cues elicited significant antipredator responses relative to the wellwater controls (Figure 2). No significant difference was detected in alarm response intensity induced by the different Atlantic salmon chemical alarm cues. In response to injections of these alarm cues, the number of feeding attempts significantly decreased from 10.1 to 6.2 attempts (averaged values; Figure 2A), the time spent moving significantly decreased from 58.0 to 32.7 $\mathrm{s}$ (Figure 2B), and the time spent motionless on the substrate significantly increased from 211.8 to $233.5 \mathrm{~s}$ (Figure 2C) relative to the changes observed for the well-water control. The response to the heterospecific (eastern blacknose dace) alarm cue for all behavioral measures was intermediate between responses observed for the Atlantic salmon alarm cues and those observed for the well-water control (Figure 2). Onesample $t$-test revealed that for the well-water control, the difference scores (i.e., the intensity of the response) for all behavioral measures were not statistically different from zero. No baseline activity difference between treatments existed in mean number of feeding attempts $\left(F_{4,59}=0.473, P=0.756\right)$, time spent moving $\left(F_{4,59}=1.165, P=0.336\right)$, and time spent on the substrate $\left(F_{4,59}=0.365, P=0.833\right)$.

\section{Experiment 2: Testing for Different Population Sensitivities to Alarm Cues}

The alarm response intensity of juvenile Atlantic salmon was significantly higher (see below) in the neutral Catamaran Brook environment than in the weakly acidic Devil's Brook $\left(F_{7,88}=5.10, P<0.01\right)$. Overall, there was no significant effect of fish origin (Atlantic salmon captured from either Catamaran Brook or Devil's Brook; $F_{7,88}=0.53, P=0.589$ ) or stimulus type (alarm cue versus stream water; $F_{7,88}=$ 2.67, $P=0.075$ ), and the origin $\times$ stimulus type interaction was not significant $\left(F_{7,88}=0.034, P=\right.$ 0.966). We found, however, a highly significant interaction between stimulus type and enclosure location $\left(F_{7,88}=8.52, P<0.001\right)$, suggesting that the effect of stimulus type was dependent on stream $\mathrm{pH}$. Post hoc comparisons of each stream taken separately showed a significant effect of stimulus type $\left(F_{3,44}=8.529, P=0.001\right)$ on the number of feeding attempts (decrease from 11.2 to 7.3 attempts; $F_{3,44}=$ 12.26, $P=0.001$; Figure 3A) and the time spent moving (decrease from 64.5 to $45.5 \mathrm{~s} ; F_{3,44}=6.53, P=$ 0.014; Figure 3B) in Catamaran Brook. Fish origin had no effect on the intensity of the alarm response $\left(F_{3,44}=\right.$ $0.565, P=0.571)$ and the origin $\times$ stimulus type
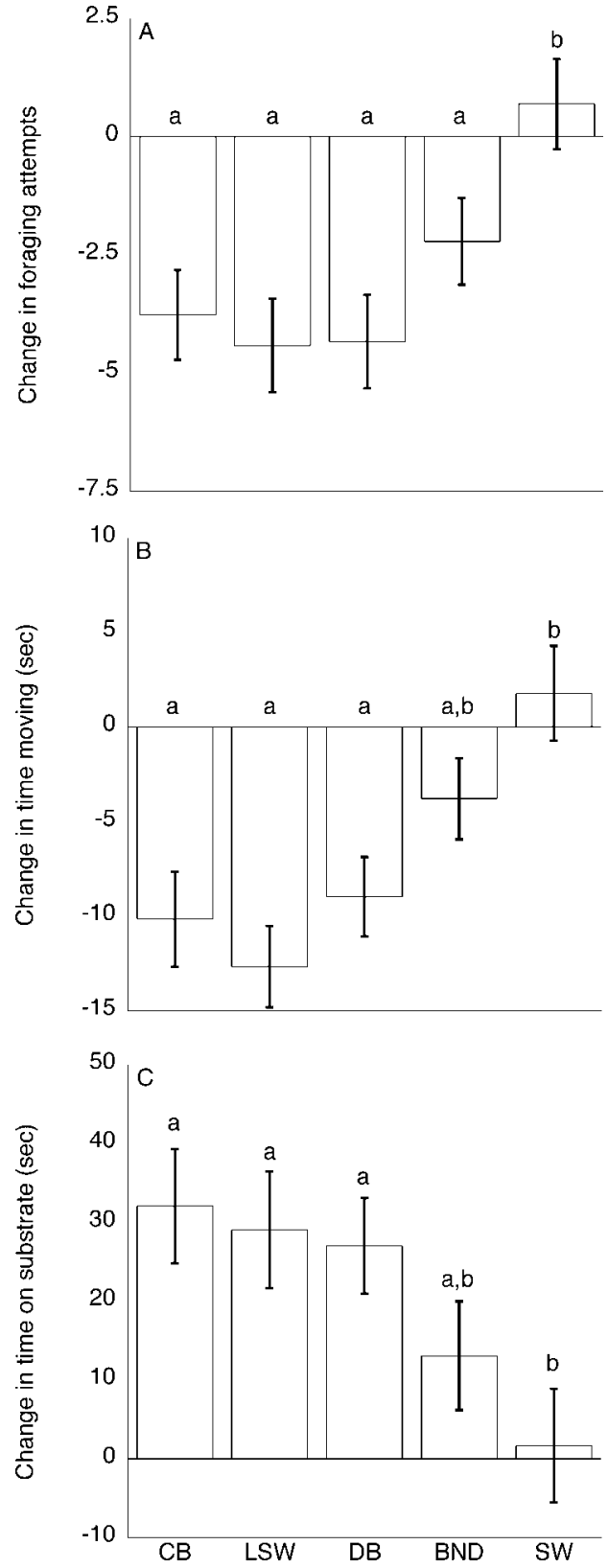

FIGURE 2.-Mean ( \pm SE) differences in behavior (poststimulus minus prestimulus) of juvenile Atlantic salmon exposed to alarm cues under $\mathrm{pH}$ neutral conditions in Catamaran Brook (CB), New Brunswick: (A) number of feeding attempts, (B) time (s) spent in motion, and (C) time (s) spent motionless on the substrate. Alarm cues were from Atlantic salmon collected at three sites $(\mathrm{CB}$; LSW $=$ Little Southwest Miramichi River; $\mathrm{DB}=$ Devil's Brook) or from a heterospecific donor $(\mathrm{BND}=$ eastern blacknose dace from $\mathrm{CB}$ ); stream water (SW) was applied as a control. Differing lowercase letters denote significant differences between treatment groups. 

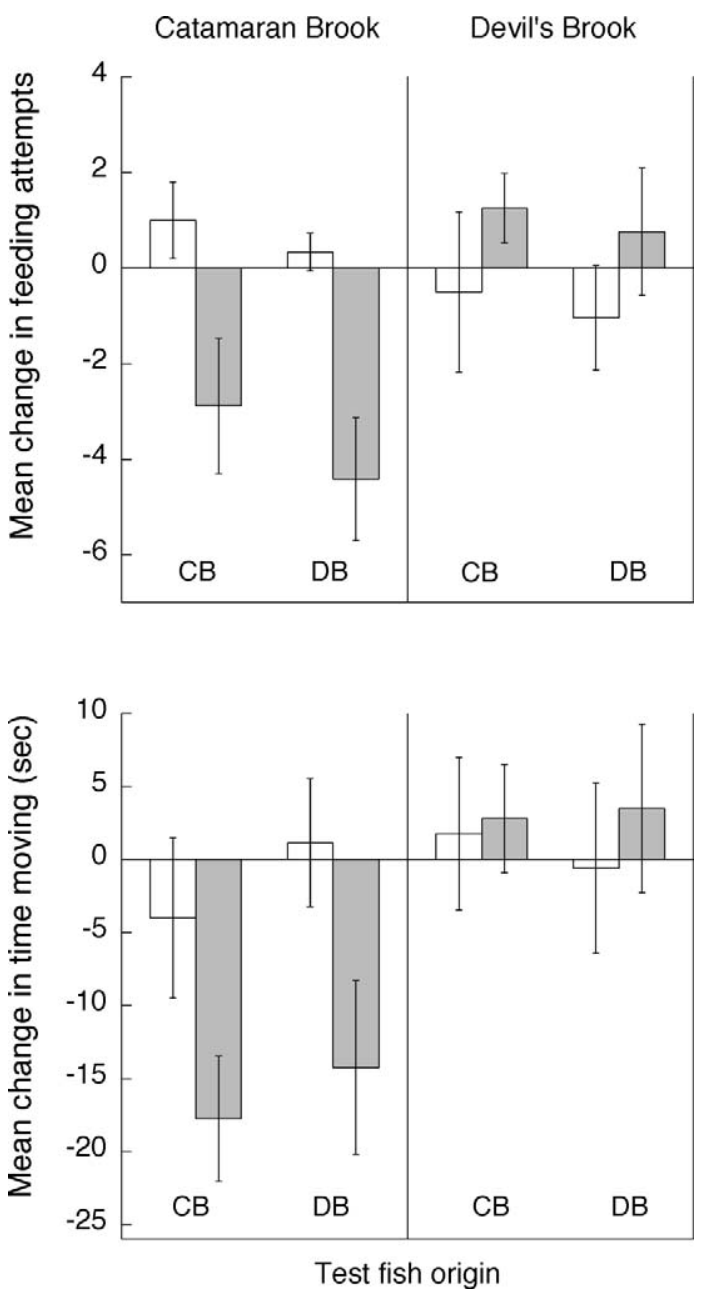

FIGURE 3.-Mean ( \pm SE) differences in behavior (poststimulus minus prestimulus) of juvenile Atlantic salmon exposed to alarm cues (dark bars) or stream water (open bars) while being held in enclosures: (upper) number of feeding attempts and (lower) time (s) spent in motion. The site of testing (Catamaran Brook [neutral pH] or Devil's Brook [acidic pH], New Brunswick) is indicated at the top of the figure; test fish origin is designated by codes $(\mathrm{CB}=$ Catamaran Brook; $\mathrm{DB}=$ Devil's Brook).

interaction was not significant $\left(F_{3,44}=0.096, P=\right.$ 0.909) for Catamaran Brook. By contrast, in Devil's Brook, we found no significant effect of stimulus type ( $\left.F_{3,44}=1.124, P=0.334\right)$ on the number of feeding attempts (increase from 10.7 to 11.8 attempts; $F_{3,44}=$ $1.97, P=0.167$; Figure $3 \mathrm{~A}$ ) or on the time spent in motion (increase from 69.7 to $72.2 \mathrm{~s} ; F_{3,44}=0.15, P=$ 0.697; Figure 3B). As in Catamaran Brook, fish origin had no effect on the intensity of the alarm response in
Devil's Brook $\left(F_{3,44}=1.12 P=0.331\right)$, and the origin $\times$ stimulus type interaction was not significant $\left(F_{3,44}=\right.$ $0.76, P=0.927)$. As such, under acidic conditions, Atlantic salmon of both stream origins were equally unresponsive to the alarm cues.

We found no significant difference in overall baseline activity of fish between the two enclosure locations $\left(F_{7,88}=2.084, P=0.130\right)$, between stream origin types $\left(F_{7,88}=0.781, P=0.46\right)$, or between stimulus treatments $\left(F_{7,88}=0.622, P=0.432\right)$; interactions of these factors were not significant. This further confirms that any observed differences in response patterns are not due to differences in activity levels between populations. Likewise, with the exception of water $\mathrm{pH}$ and conductivity, we found no significant difference in the mean values for any of the abiotic variables surveyed (Table 3).

\section{Discussion}

Our experiments confirm earlier studies demonstrating that acidity impairs the ability to respond to waterborne chemical alarm cues. We extend the results of those studies by showing that the apparent disparity in alarm cue response between Atlantic salmon reared under different acidity regimes is driven by environmental differences in water quality rather than by intrinsic differences in the fish's ability to produce or respond to the alarm cues. In experiment 1 , we demonstrated that alarm cues originating from Atlantic salmon reared in neutral and weakly acidic streams were equally effective in eliciting antipredator behavior when tested under neutral conditions. Noticeably, no difference existed in the intensity of the alarm response after alarm cues of differing origins were injected (although the eastern blacknose dace alarm cue elicited only a weak alarm response; Figure 2). Thus, the observed differences in antipredator behavior found between our neutral and weakly acidic streams cannot be attributed to any effects on the production (either quality or quantity) of the alarm cues between Atlantic salmon reared under different conditions. The reciprocal transplants of fish in experiment 2 showed no difference in the fish's ability to respond to alarm cues, demonstrating that long-term olfactory impairment could not account for reduced aptitude to respond to the alarm cues. In experiment 2, we showed that test fish origin had no effect on the intensity of the response to alarm cues when tested under neutral or acidic $\mathrm{pH}$. When tested under neutral conditions, fish from both neutral and weakly acidic streams performed the predicted antipredator behavior without a significant difference in response intensity; under acidic conditions, neither fish population responded to conspecific chemical alarm cues. This clearly demonstrates that 
environmental acid-mediated chemosensory disruption explains the differences in alarm response intensity between sites rather than state-dependent differences in Atlantic salmon physiological or behavioral conditions. These results suggest that (1) short-term reduction in olfactory sensitivity, (2) chemical disruption of the alarm cues, or (3) a combination of these is creating significant functional impairment, impeding Atlantic salmon response to the alarm cues. Overall, these finding reinforce the conclusion that intersite differences in alarm response can be explained by an environmental acid-mediated chemosensory disruption rather than by state-dependent (physiological and behavioral) differences. For instance, when comparing all the measured environmental variables between test sites, only the environmental acidity and conductivity levels significantly differed. Conductivity may represent the contribution of ion-rich groundwater coming into the stream, leading to greater buffering capacity and, hence, circumneutral conditions (Woessner 2000).

The impact of weak acidification (or low concentrations of various other pollutants) has only recently received well-deserved attention (reviewed by Lürling and Scheffer 2007), showing various subtle sublethal costs linked to maladaptive response patterns. In our study, the $\mathrm{pH}$ ranged from approximately 5.9 to 7.3 and thus was considered to be below a threshold under which damage to aquatic biota typically occurs (Doka et al. 2003; Holt et al. 2003). This acidity level does not typically create severe physiological stress in many freshwater fish species; for salmonids, the acidity avoidance threshold is between $\mathrm{pH} 4.5$ and 5.5 (Lacroix et al. 1985; Gunn 1986; Peterson et al. 1989), values significantly more acidic than those in our test streams. Although low-level acidity may not have direct lethal effects for wild juvenile salmonids, the observed chemosensory alarm impairment may have severe fitness consequences stemming from increased predator success. Although this hypothesis requires testing under a natural setting, Leduc et al. (in press) showed increased predator success under laboratory conditions during staged encounters between predators and prey. In that experiment (Leduc et al., in press), largemouth bass Micropterus salmoides predators captured rainbow trout Oncorhynchus mykiss prey significantly faster when alarm cues acidified to a $\mathrm{pH}$ of approximately 6.0 were injected into the test tanks compared with injections of neutral alarm cues. This result clearly shows the ecological relevance of a reduced ability to respond to chemical alarm cues because of chemosensory impairment. Other studies have shown maladaptive but nonlethal behavioral changes in salmonids exposed to low acid concentrations. For example, Kitamura and Ituka (2000, 2001) documented suppression of normal mating, nest digging, and migratory behaviors in wild hime salmon (landlocked sockeye salmon $O$. nerka) under a $\mathrm{pH}$ of approximately 6.2. Thus, nonlethal anthropogenic acidification may broadly affect organisms' behavior and life histories, thereby affecting their ecology. In the case of wild Atlantic salmon, the decreased number of adults returning to spawn may render this species increasingly vulnerable to sublethal anthropogenic changes (Parrish et al. 1998). The impairment mechanisms proposed by our results suggest that reductions in acid depositions could have immediate favorable effects on the normal ability of Atlantic salmon to detect chemical alarm cues and respond in a contextappropriate manner.

Recent research on ostariophysan fishes has demonstrated increased production of chemical alarm cues upon exposure to skin pathogens, parasites, and ultraviolet-B radiation (Chivers et al. 2007). Given the possible immunological function of alarm cues, it is easy to understand why their production is maintained even under conditions in which the predator avoidance function is lacking (e.g., under low pH). If such a predator avoidance function no longer becomes adaptive, how is this trait maintained in the alarm cue receivers? It might be expected that a trait for which the value is reduced or lost due to an environmental change should disappear (Ricker 1972). However, in our experiment 2, the intrinsic abilities to detect and respond to chemical alarm cues were maintained under acidic conditions (as revealed when tested under neutral conditions) despite the loss of predator avoidance benefits under acidic home stream conditions. How can this apparent lack of divergence in chemosensory functions between acidic and neutral conditions (either for local adaptation in detection abilities or a complete detection loss) be maintained? Gene flow from salmonids moving into nonnatal spawning streams may be substantial (Tallman and Healey 1994; Hendry 2001; Rogers and Curry 2004). In our test system, the patch size of the acidic selection regime may be small relative to gene flow from Atlantic salmon found in neutral conditions, where chemical alarm traits remain adaptive. It is thus possible that the acidic patch size may be too small, preventing local divergence (Sandoval 1994). Moreover, the level of acidification in the acidic stream may not have been present for a sufficient duration to generate divergence. However, population differences driven by selection regimes may act on relatively short time scales (Hendry and Quinn 1997; Hendry et al. 2002). Pink salmon O. gorbuscha and sockeye salmon diverged genetically from their common ancestral group over approximately 12-13 generations (Gharrett 
and Thomason 1987; Hendry 2001). Acid precipitations in the Canadian Atlantic Provinces have been occurring for at least 60 years (Clair and Ehrman 1995) and thus over at least 10-12 generations. It remains unclear whether acidity as a selection regime would produce local chemosensory adaptation (or complete detection loss) under acidic conditions in future generations of Atlantic salmon if environmental conditions do not improve.

Although recent research has reported a widespread recovery from acidification in North American and European aquatic ecosystems in response to a decrease in sulfate deposition (Stoddard et al. 1999; Doka et al. 2003; but see Alewell et al. 2000), several estimates predict that 50 years or even 100 years will be necessary for acid-neutralizing capacity to return aquatic systems to preacidification levels (Jeffries et al. 2000; Clair et al. 2004). Stoddard et al. (1999) suggested that a larger decrease in sulfur deposition, a longer response time, or both may be required for a widespread recovery to occur in North America. As such, the occurrence of sublethal acidity and its impacts on aquatic ecosystems will probably be measurable for many more decades. Under present conditions, we have shown that differences in the display of functional chemical alarm traits (i.e., the production of and response to chemical alarm cues) are not caused by physiological or behavioral differences between salmonids reared under different acidification regimes. Rather, our data suggest environmentally dependent effects occurring under weakly acidic conditions whereby a reduction of olfaction abilities, degradation of functional alarm cues, or both lead to an impaired alarm response. Fortunately, these impairment mechanisms appear to be reversible in the short term if environmental conditions improve.

\section{Acknowledgments}

The authors thank Dr. James Grant and Nathalie Brodeur for helpful comments on early versions of this manuscript. Appreciation is extended to Dr. Rick Cunjak and the Catamaran crew for their generous assistance during the field experiment. Comments from three anonymous reviewers were also of valuable help in improving this manuscript. All work reported herein has been conducted in accordance with Concordia University's Animal Care Protocol Number AC-2005BROW. Financial support was provided by Concordia University and the Natural Science and Engineering Research Council (NSERC) of Canada to G.E.B., an NSERC Postgraduate D2 Scholarship to A.O.H.C.L., and the Atlantic Salmon Federation Olin Fellowship. This paper is Contribution Number 96 to the Catamaran Brook Habitat Research Project.

\section{References}

Abrams, P. A. 1995. Implications of dynamically variable traits for identifying, classifying, and measuring direct and indirect effects in ecological communities. American Naturalist 146:112-134.

Alewell, C., B. Manderscheid, H. Meesenburg, and J. Bittersohl. 2000. Is acidification still an ecological threat? Nature 407:856-857.

Atchison, G. J., M. G. Henry, and M. B. Sandheinrich. 1987. Effects of metals on fish behaviour: a review. Environmental Biology of Fishes 18:11-25.

Åtland, A. 1998. Behavioural responses of brown trout, Salmo trutta, juveniles in concentration gradients of $\mathrm{pH}$ and $\mathrm{Al}$-a laboratory study. Environmental Biology of Fishes 53:331-34.

Blanchet, S., J. J. Dodson, and S. Brosse. 2006. Influence of habitat structure and fish density on Atlantic salmon Salmo salar L. territorial behaviour. Journal of Fish Biology 68:951-957.

Brown, G. E. 2003. Learning about danger: chemical alarm cues and local risk assessment in prey fishes. Fish and Fisheries 4:227-234.

Brown, G. E., and D. P. Chivers. 2005. Learning as an adaptive response to predation within aquatic ecosystem. Pages 34-54 in P. Barbosa and I. Castellano. editors. Ecology of predator-prey I nteractions. Oxford University Press, Oxford, UK.

Brown, G. E., J. C. Adrian Jr., M. G. Lewis, and J. M. Tower. 2002. The effects of reduced $\mathrm{pH}$ on chemical alarm signaling in ostariophysan fishes. Canadian Journal of Fisheries and Aquatic Sciences 59:1331-1338.

Brown, S. B., R. E. Evans, B. E. Thompson, and T. J. Hara. 1982. Chemoreception and aquatic pollutants. Pages 363-393 in T. J. Hara editor. Chemoreception in fishes. Elsevier, Amsterdam.

Brown, G. E., P. E. Foam, H. E. Cowell, P. Guevara-Fiore, and D. P. Chivers. 2004. Production of chemical alarm cues in convict cichlids: the effects of diet, body condition and ontogeny. Annales Zoologici Fennici 41:487-499.

Chivers, D. P., R. S. Mirza, and J. G. Johnston. 2002. Learned recognition of heterospecific alarm cues enhances survival during encounters with predators. Behaviour 139:929-938.

Chivers, D. P., and R. J. F. Smith. 1998. Chemical alarm signaling in aquatic predator-prey systems: a review and prospectus. Écoscience 5:315-321.

Chivers, D. P., B. D. Wisenden, C. J. Hindman, T. A. Michalak, R. C. Kusch, S. G. W. Kaminskyj, K. L. Jack, M. C. O. Ferrari, R. J. Pollock, C. F. Halbgewachs, M. S. Pollock, S. Alemadi, C. T. James, R. K. Savaloja, C. P. Goater, A. Corwin, R. S. Mirza, J. M. Kiesecker, G. E. Brown, J. C. Adrian Jr., P. H. Krone, A. R. Blaustein, and A. Mathis. 2007. Epidermal "alarm substance" cells of fishes maintained by non-alarm functions: possible defence against pathogens, parasites and UVB radiation. Proceedings of the Royal Society of London Series B 274:2611-2619.

Clair, T. A., I. F. Dennis, P. G. Amiro, and B. J. Cosby. 2004. Past and future chemistry changes in acidified Nova Scotian Atlantic salmon (Salmo salar) rivers: a dynamic 
modeling approach. Canadian Journal of Fisheries and Aquatic Sciences 61:1965-1975.

Clair, T. A., and J. M. Ehrman. 1995. Acid precipitationrelated chemical trends in 18 rivers of Atlantic Canada, 1983-1992. Environmental Monitoring and Assessment 35:165-179.

Cunjak, R. A. 1995. Addressing forestry impacts in the Catamaran Brook basin: an overview of the pre-logging phase. Page 203 in M. Chadwick editor. Water, science and the public: the miramichi ecosystem. Canadian Special Publication of Fisheries and Aquatic Sciences 123.

Cunjak, R. A., D. Caissie, N. El-Jabi, P. Hardie, J. H. Conlon, T. L. Pollock, D. J. Giberson, and S. KomadinaDouthwright. 1993. The Catamaran Brook (New Brunswick) habitat research project: biological, physical and chemical conditions (1990-1992). Canadian Technical Report of Fisheries and Aquatic Sciences 1914.

Department of Energy, Mines, and Resources Canada. 1991. The potential of soils and bedrock to reduce the acidity of atmospheric deposition. Map scale 1:7,500,000. Call Number MCR 4157F. Her Majesty the Queen in Right of Canada, Ottawa.

Doka, S. E., D. K. McNicol, M. L. Mallory, I. Woog, C. K. Minns, and N. D. Yan. 2003. Assessing potential for recovery of biotic richness and indicator species due to changes in acidic deposition and lake $\mathrm{pH}$ in five areas of southeastern Canada. Environmental Monitoring and Assessment 88:53-101.

Gharrett, A. J., and M. A. Thomason. 1987. Genetic changes in pink salmon (Oncorhynchus gorbuscha) following their introduction into the Great Lakes. Canadian Journal of Fisheries and Aquatic Sciences 44:787-792.

Grant, J. W. A., S. Ó. Steingrímsson, E. R. Keely, and R. A. Cunjak. 1998. Implications of territory size for the measurement and prediction of salmonid abundance in streams. Canadian Journal of Fisheries and Aquatic Sciences 55:181-190.

Gunn, J. M. 1986. Behaviour and ecology of salmonids fishes to episodic $\mathrm{pH}$ depression. Environmental Biology of Fishes 17:241-252.

Hendry, A. P. 2001. Adaptive divergence and the evolution of reproductive isolation in the wild: an empirical demonstration using introduced sockeye salmon. Genetica 112113:515-534.

Hendry, A. P., and T. P. Quinn. 1997. Variation in adult life history and morphology among Lake Washington sockeye salmon (Oncorhynchus nerka) populations in relation to habitat features and ancestral affinities. Canadian Journal of Fisheries and Aquatic Sciences $54: 75-84$.

Hendry, A. P., E. B. Taylor, and D. J. McPhail. 2002. Adaptive divergence and the balance between selection and gene flow: lake and stream stickleback in the Misty system. Evolution 56:1199-1216.

Holt, C. A., N. D. Yan, and K. M. Somers. 2003. pH 6 as threshold use in critical load modeling for zooplankton community change with acidification in lakes of southcentral Ontario: accounting for morphometry and geography. Canadian Journal of Fisheries and Aquatic Sciences 60:151-158.

Imre, I., J. W. A. Grant, and E. R. Keely. 2002. The effect of visual isolation on territory size and population density of juvenile rainbow trout (Oncorhynchus mykiss). Canadian Journal of Fisheries and Aquatic Sciences 59:303-309.

Jeffries, D. S., D. C. L. Lam, I. Wong, and M. D. Moran. 2000. Assessment of changes in lake $\mathrm{pH}$ in southeastern Canada arising from present levels and expected reductions in acidic deposition. Canadian Journal of Fisheries and Aquatic Sciences 57:40-49.

Johnston, T. A. 1997. Downstream movements of young-ofthe-year fishes in Catamaran Brook and the Little Southwest Miramichi River, New Brunswick. Journal of Fish Biology 51:1047-1062.

Keeley, E. R., and J. W. Grant. 1995. Allometric and environmental correlates of territory size in juvenile Atlantic salmon (Salmo salar). Canadian Journal of Fisheries and Aquatic Sciences 52:186-196.

Kitamura, S., and K. Ituka. 2000. Acidification severely suppresses spawning of hime salmon (land-locked sockeye salmon, Oncorhynchus nerka). Aquatic Toxicology 51:107-113.

Kitamura, S., and K. Ituka. 2001. Effects of acidification on salmonid spawning behavior. Water, Air, and Soil Pollution 130:875-880.

Lacroix, G. L., D. J. Gordon, and D. J. Johnston. 1985. Effects of low environmental $\mathrm{pH}$ on the survival, growth and ionic composition of post-emergent Atlantic salmon (Salmo salar). Canadian Journal of Fisheries and Aquatic Sciences 42:768-775.

Leduc, A. O. H. C., J. M. Kelly, and G. E. Brown. 2004. Detection of conspecific alarm cues by juvenile salmonids under neutral and weakly acidic conditions: laboratory and field tests. Oecologia 139:318-324.

Leduc, A. O. H. C., E. Roh, C. Breau, and G. E. Brown. 2007. Effects of ambient acidity on chemosensory learning: example of an environmental constraint on acquired predator recognition in wild juvenile Atlantic salmon (Salmo salar). Ecology of Freshwater Fish 16:385-394.

Leduc, A. O. H. C., E. Roh, and G. E. Brown. In press. Effects of acid rainfall on juvenile Atlantic salmon (Salmo salar) antipredator behaviour: loss of chemical alarm function and potential survival consequences during predation. Marine and Freshwater Research.

Leduc, A. O. H. C., E. Roh, M. C. Harvey, and G. E. Brown. 2006. Impaired detection of chemical alarm cues by wild Atlantic salmon (Salmo salar) in an acidic environment? Canadian Journal of Fisheries and Aquatic Sciences 63:2356-2363.

Lima, S. L. 1998. Nonlethal effects in the ecology of predatorprey interactions. Bioscience 48:25-34.

Lima, S. L., and L. M. Dill. 1990. Behavioral decisions made under the risk of predation: a review and prospectus. Canadian Journal of Zoology 68:619-640.

Little, E. E., R. D. Archeski, B. A. Flerov, and V. I. Kozlovskaya. 1990. Behavioral indicator of sublethal toxicity in rainbow trout. Archives of Environmental Contamination and Toxicology 19:380-385.

Lürling, M., and M. Scheffer. 2007. Info-disruption: pollution and the transfer of chemical information between organisms. Trends in Ecology and Evolutions 22:374379.

Mathis, A., D. P. Chivers, and R. J. F. Smith. 1996. Cultural transmission of predator recognition in fishes: intraspe- 
cific and interspecific learning. Animal Behaviour 51:185-201.

Mathis, A., and R. J. F. Smith. 1993. Chemical labeling of northern pike (Esox lucius) by the alarm pheromone of fathead minnows (Pimephales promelas). Journal of Chemical Ecology 19:1967-1979.

McPherson, T. D., R. S. Mirza, and G. G. Pyle. 2004. Responses of wild fishes to alarm chemicals in pristine and metal-contaminated lakes. Canadian Journal of Zoology 82:694-700.

Mirza, R. S., and D. P. Chivers. 2000. Predator-recognition training enhances survival of brook trout: evidence from laboratory and field-enclosure studies. Canadian Journal of Zoology 78:2198-2208.

Mirza, R. S., and D. P. Chivers. 2003. Response of juvenile rainbow trout to varying concentrations of chemical alarm cue: response thresholds and survival during encounters with predators. Canadian Journal of Zoology 81:88-95.

Moore, A. 1994. An electrophysiological study on the effects of $\mathrm{pH}$ on olfaction in mature male Atlantic salmon (Salmo salar) parr. Journal of Fish Biology 45:493-502.

Parrish, D. L., R. J. Behnke, S. R. Gephard, S. D. McCormick, and G. H. Reeves. 1998. Why aren't there more Atlantic salmon (Salmo salar)? Canadian Journal of Fisheries and Aquatic Sciences 55(Supplement 1):281-287.

Peterson, R. H., K. Coombs, J. Power, and U. Paim. 1989. Response of several fish species to $\mathrm{pH}$ gradients. Canadian Journal of Zoology 67:1566-1572.

Persons, M. H., S. E. Walker, A. L. Rypstra, and S. D. Marshall. 2001. Wolf spider predator avoidance tactics and survival in the presence of diet-associated predator cues (Araneae: Lycosidae). Animal Behaviour 61:43-51.

Ricker, W. E. 1972. Hereditary and environmental factors affecting certain salmonid populations. Pages 27-160 in R. C. Simon and P. A. Larkin. editors. The stock concept in Pacific salmon. H. R. MacMillan lectures in fisheries. University of British Columbia, Vancouver.

Rodhe, H. L., J. Gallardo, and L. Kjellström. 1995. Global scale transport of acidifying pollutants. Water, Air, and Soil Pollution 85:37-50.

Rogers, S. M., and A. R. Curry. 2004. Genetic population structure of brook trout inhabiting a large river watershed. Transactions of the American Fisheries Society 133:1138-1149.

Roh, E., R. S. Mirza, and G. E. Brown. 2004. Quality or quantity? The role of donor condition in the production of chemical alarm cues in juvenile convict cichlids. Behaviour 141:1235-1248.

Rosenfeld, J. S., and S. Boss. 2001. Fitness consequences of habitat use for juvenile cutthroat trout: energetic costs and benefits in pools and riffles. Canadian Journal of Fisheries and Aquatic Sciences 58:585-593.

Sandahl, J. F., D. H. Baldwin, J. J. Jenkins, and N. Scholz. 2007. A sensory system at the interface between urban stormwater runoff and salmon survival. Environmental Sciences and Technology 41:2998-3004.

Sandoval, C. P. 1994. The effects of the relative geographic scales of gene flow and selection on morph frequencies of the walking-stick Timena cristinae. Evolution 48:1866-1879.

Schindler, D. W. 1988. Effects of acid rain on freshwater ecosystems. Science 239:149-157.

Scholz, N. L., N. K. Truelove, B. L. French, B. A. Berejikian, T. P. Quinn, E. Casillas, and T. K. Collier. 2000. Diazinon disrupts antipredator and homing behaviors in Chinook salmon (Oncorhynchus tshawytscha). Canadian Journal Fisheries and Aquatic Sciences 57:1911-1918.

Scott, G. R., K. A. Sloman, C. Rouleau, and C. M. Wood. 2003. Cadmium disrupts behavioural and physiological response to alarm substance in juvenile rainbow trout (Oncorhynchus mykiss). Journal of Experimental Biology 206:1779-1790.

Smith, R. J. F. 1992. Alarm signal in fishes. Reviews in Fish Biology and Fisheries 2:33-63.

Smith, R. J. F. 1999. What good is smelly stuff in the skin? Cross function and cross taxa effects in fish "alarm substances". Page 475-487 in R. E. Johnston, D. MüllerSchwarze, and P. W. Sorensen. editors. Advances in chemical signals in vertebrates. Kluwer, New York.

Smith, J. J., A. O. H. C. Leduc, and G. E. Brown. 2008. Chemically mediated learning in juvenile rainbow trout: does predator odour $\mathrm{pH}$ influence intensity and retention of acquired predator recognition? Journal of Fish Biology 72:1750-1760.

Steingrímsson, S. Ó., and J. W. A. Grant. 2003. Patterns and correlates of movement and site fidelity in individually tagged young-of-the-year Atlantic salmon (Salmo salar). Canadian Journal of Fisheries and Aquatic Sciences 60:193-202.

Stoddard, J. L., D. S. Jeffries, A. Lukewille, T. A. Clair, P. J. Dillon, C. T. Driscoll, M. Forsius, M. Johannessen, J. S. Kahl, J. H. Kellogg, A. Kemp, J. Mannio, D. Monteith, P. S. Murdoch, S. Partick, A. Rebsdorf, B. L. Skjelkvale, M. P. Stainton, T. Traaen, H. van Dam, K. E. Webster, J. Wieting, and A. Wilander. 1999. Regional trends in aquatic recovery from acidification in North America and Europe. Nature (London) 401:575-578.

Tallman, R. F., and M. C. Healey. 1994. Homing, straying, and gene flow among seasonally separated populations of chum salmon (Oncorhynchus keta). Canadian Journal of Fisheries and Aquatic Sciences 51:577-588.

Tembo, R. N. 2009. The sublethal effects of low-pH exposure on the chemoreception of Poecilia sphenops. Archives of Environmental Contamination and Toxicology 57:157163.

Turner, A. M., R. J. Bernot, and C. M. Boes. 2000. Chemical cues modify species interactions: the ecological consequences of predator avoidance by freshwater snails. Oikos 88:148-158.

Wisenden, B. D. 2000. Olfactory assessment of predation risk in aquatic environment. Philosophical Transactions of the Royal Society of London Series B 355:1205-1208.

Woessner, W. W. 2000. Stream and fluvial plain ground water interactions: rescaling hydrogeologic thought. Ground Water 38:423-429. 